\title{
Evaluation And Maintenance of Road Damage In Sidotopo Surabaya Road Using Pavement Condition Index (PCI) Method
}

\author{
Ibnu Sholichin ${ }^{1}$, Nugroho Utomo \\ Department of Civil Engineering \\ Universitas Pembangunan Nasional "Veteran" Jawa Timur \\ Surabaya, Indonesia \\ 1ibnu1609@gmail.com
}

\begin{abstract}
Road damage is caused by overloaded and repeated traffic loads, heat or air temperature, water and rain, as well as poor asphalt quality, so the road must be maintained properly in order to serve traffic growth during the life of the plan. Routine and periodic road maintenance needs to be carried out to maintain road safety and comfort for users and durability until the age of the plan. Survey of pavement conditions is necessary to be carried out periodically, both structural and nonstructural, to determine the level of road service available. Included in the nonstructural examination, are the roughness, texture, and skid resistance. Based on the results of PCI analysis, Sidotopo road includes poor levels with PCI values below 40. From the situation analysis, damage is caused by high traffic volumes and excessive and repetitive vehicle loads.
\end{abstract}

Keywords-Sidotopo Surabaya road; pavement condition index (PCI) method

\section{INTRODUCTION}

Sidotopo Road is a very important road. On Sidotopo road there is a train station that used especially for freight or cargo transportation. This station serves as a place to loading and unloading goods in and out of town. To support the loading and unloading activities, there is a truck terminal that transports goods from or out of Surabaya. So this Sidotopo road is a busy road with traffic dominated by trucks. Due to heavy and repetitive loads, the Sidotopo road is often damaged [1], [2].

The high frequency of vehicles crossing the road surface causes a decrease in the level of road service in the form of damage to the road surface. Therefore, it is necessary to conduct a review, to determine the damage and the type of damage caused by traffic loads, weather changes, and other bad influences that are very influential and inhibit the smooth traffic [3]. Good road conditions will facilitate population mobility in carrying out daily activities [4]. [5], [6]:

Damages to road pavement construction can be caused by

- Traffic can be in the form of an increase and repetition of a load.
- Water can be rainwater, or due to poor drainage systems, and rising water due to capillarity.

- Material for pavement construction, in this case, caused by the nature of the material itself or it can also be caused by an improper material management system.

- Climate, Indonesia has a tropical climate where air temperature and rainfall are generally high, which is one of the causes of road damage.

- Subgrade conditions that are not stable, probably caused by implementation systems that is not good, or can be caused by bad soil nature.

- The process of compacting the layer above the ground is not good.

Generally, the damage that arises is not caused by just one factor, but it could be a combination of interrelated factors, for example, the edge crack, can initially be caused by the improper support from the side. With the edge cracking, allowing water to seep into the layer below which weakens the bond between asphalt and aggregate, this can cause holes in addition to the carrying capacity of the layer below [7]

The importance of planning a management system is the ability to determine work and assessment of existing pavement conditions with the aim of identifying the conditions of the pavement layer [8]. Pavement Condition Index (PCI) is an estimate of road conditions with a rating system to state the actual pavement conditions with reliable and objective data. The PCI method was developed in the United States by the U.S Corps of Engineer for airport pavement, highway and parking areas because this method obtained accurate data and estimated conditions according to conditions in the field. PCI level is written in the level 0-100 [9], [10].

Road pavement conditions are divided into several levels as follows:

- Perfect (Excellent): If the PCI value in one sample area reaches $85-100$. 
- Very Good: If the PCI value in one sample area reaches 70-85.

- Good: If the PCI value in one sample area reaches 55-70.

- Fair: If the PCI value in one sample area reaches 40-55.

- Poor: If the PCI value in one sample area reaches 25-40.

- Very Poor (Very Poor): If the PCI value in one sample area reaches 10-25.

- Failed: If the PCI value in one sample area reaches 0-10.

To analyze the damage to the Sidotopo Surabaya road, the PCI method was used. PCI is the level of the pavement surface condition and its size in terms of the carrying capacity function which refers to the conditions and damage on the surface of the pavement that occurs. The PCI method is used because the measurement is more specific so that the evaluation and accuracy produced are more measurable than other methods. The expected results of this study are knowing the level and causes of road damage and finding solutions for road improvement [11].

\section{METHODS}

The stages of the PCI are:

- Divide the Sidotopo road into several segments to ease the work. The Sidotopo road is divided into 3 segments, namely:
a. STA $0+00-$ STA $0+433$
b. STA $0+433-$ STA $0+866$
c. STA $0+866+$ STA $0+1,300$

- Survey of road damage is adjusted to the type of damage.

- Calculate Density: Density is the percentage of the area of damage to the sample area of the unit being reviewed. Formula looking for density values:

$$
\text { Density }=\frac{\mathrm{Ad}}{\mathrm{As}} \times 100 \%
$$

or

$$
\text { Density }=\frac{\mathrm{Ld}}{\mathrm{As}} \times 100 \%
$$

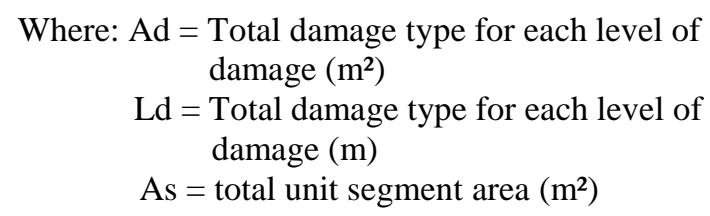

- Deduct Value (DV): After the density value is obtained, then each type of damage is entered based on its value to the graph according to the level of damage to find the value of the deduct value.
- Total Deduct Value (TDV): Total Deduct Value that obtained from each segment that is reviewed is summed to obtain the total Deduct Value.

- The requirement to get the q value is determined by the number of individual deduct values that greater than 5 in each segment of the road segment studied.

- The CDV value can be searched after the q value is known by adding up the value of the deduct value and then entering the amount of deduct value as seen in the CDV graphic image. After the CDV value is known, the PCI value can be determined by using the following formula:

$$
\mathrm{PCI}=100-\mathrm{CDV}
$$

After the PCI value is known, the rating of the unit sample will be determined by using a graph. Furthermore, to calculate the overall PCI value in one road segment can be calculated using the following formula:

$$
\mathrm{PCI}=\frac{\sum P C I}{N}
$$

Where:

$$
\begin{array}{ll}
\sum_{\mathrm{N}} \mathrm{PCI} & =\text { Total PCI value in one road } \\
& =\text { Number of segments in one road }
\end{array}
$$

\begin{tabular}{|c|c|c|}
\hline \multicolumn{3}{|c|}{ Condition Survey Data Sheet for Sample Unit } \\
\hline $\begin{array}{ll}\text { 1. } & \text { Alligator Cracking }\left(\mathrm{m}^{2}\right) \\
\text { 2. } & \text { Block Cracking }\left(\mathrm{m}^{2}\right) \\
\text { 3. Rutting }\left(\mathrm{m}^{2}\right) \\
\text { 4. Longitudinal Cracking } \\
\\
(\mathrm{m})\end{array}$ & $\begin{array}{ll}\text { 5. } & \text { Edge Dis } \\
\text { 6. } & \text { Potholes } \\
\text { 7. } & \text { Transver } \\
\text { 8. } & \text { Flushing } \\
\text { 9. } & \text { Raveling }\end{array}$ & $\begin{array}{l}(\mathrm{m}) \\
\left(\mathrm{m}^{2}\right)\end{array}$ \\
\hline Distress Severity & Quantity & Segmen \\
\hline $1 \mathrm{M}$ & 817,88 & \multirow{3}{*}{ 'I } \\
\hline $6 \mathrm{M}$ & 910,14 & \\
\hline $5 \mathrm{M}$ & 875,56 & \\
\hline $1 \mathrm{M}$ & 825,76 & \multirow{3}{*}{ II } \\
\hline $6 \mathrm{M}$ & 904,98 & \\
\hline $5 \mathrm{M}$ & 864,01 & \\
\hline $1 \mathrm{M}$ & 885,03 & \multirow{3}{*}{ III } \\
\hline $6 \mathrm{M}$ & 1002,03 & \\
\hline $5 \mathrm{M}$ & 830,3 & \\
\hline
\end{tabular}

\section{RESULT AND DISCUSSION}

The results of the survey on Sidotpo road conditions and damage included in the table consisting of type, dimension, level and location of damage. The table of conditions and road damage are documentation of road conditions in each segment and are useful for making it easy to enter road damage data in PCI Table.

TABLE I. The Results Of The Damage Survey On The Sidotopo SURABAYA ROAD 
The stages of the calculation of PCI are:

- Add every type of damage to each level of damage seen.

- Calculate Density based on segment.

Density $\%=($ damage area $/$ road area $) \times 100 \%$

Segment area I and II $=2598 \mathrm{~m}^{2}$

Segment area III $=2604 \mathrm{~m}^{2}$

Segment I :

$$
\begin{array}{ll}
\text { Alligator Cracking } & =\frac{817.88}{2598} \times 100 \%=0.31 \\
\text { Potholes } & =\frac{910.14}{2598} \times 100 \%=0.35 \\
\text { Edge Distortion } & =\frac{875.56}{2598} \times 100 \%=0.34
\end{array}
$$

Segment II :

$$
\begin{array}{ll}
\text { Alligator Cracking } & =\frac{825.76}{2598} \times 100 \%=0.31 \\
\text { Potholes } & =\frac{904.98}{2598} \times 100 \%=0.35 \\
\text { Edge Distortion } & =\frac{864.01}{2598} \times 100=0.33
\end{array}
$$

Segment III :

$$
\begin{array}{ll}
\text { Alligator Cracking } & =\frac{885.03}{2604} \times 100 \%=0.34 \\
\text { Potholes } & =\frac{1002.03}{2604} \times 100 \%=0.38 \\
\text { Edge Distortion } & =\frac{830.3}{2604} \times 100 \%=0.32
\end{array}
$$

- Calculating the deduct value after the density value is obtained, then each type of damage is entered based on its value to the graph according to the level of damage. Reduction value for calculating PCI roads with asphalt pavement surfaces. On the Sidotopo road the following damage occurs:

1. Values that indicate crocodile skin crack damage based on the deduct value are shown in Figure 1 below:

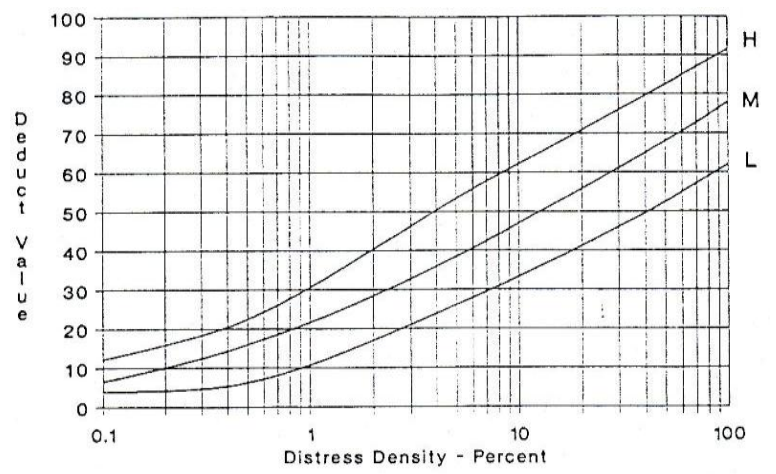

Fig. 1. Alligator Cracking Damage Graph

From Figure 1 about the graph of damage to Alligator Cracking, the results obtained from the calculation of density of 0.31 is greater than the minimum number shown on the $\mathrm{X}$-axis of the chart, which is 0.1 so that it can be shown with a graph. To illustrate the results of the calculation of distress density on the graph of crocodile skin crack damage that is equal to 0.31 drawn to intersect with the line of the curve $\mathrm{H}$, where the line of curve $\mathrm{H}$ is the level of damage. After drawing the line towards the $\mathrm{Y}$ axis so that the deduct value is 19 for segment I and II, while for segment II, the deduct value is 20 .

Level: $\mathrm{L}=$ crack lengthwise with a thin line shape that is not interconnected.

$\mathrm{M}=$ Further development of cracks with mild quality.

$\mathrm{H}=$ Cracks will be interconnected to form fragments.

2. Value that shows hole damage based on the deduct value is shown in Figure 2 below:



Fig. 2. Potholes Damage Graph

From Figure 2 about potholes damage graph, the results obtained from the calculation of density of 0.35 is greater than the minimum number shown on the $\mathrm{X}$-axis of the graph, which is 0.01 so that it can be shown on the graph. To illustrate the results of the calculation of distress density in the hole damage graph that is equal to 0.35 is drawn up to intersect with the $\mathrm{M}$ curve line, where the $\mathrm{M}$ curve line is the damage level. After that, a line is drawn towards the $\mathrm{Y}$ axis so that the deduct value is 61 for segments I and II, and 63 for segment III.

Level:

$$
\begin{aligned}
& \mathrm{L}=\text { Depth } 0.5-1 \text { inch }(12.5-25.4 \mathrm{~mm}) \\
& \mathrm{M}=1-2 \text { inch depth }(25.3-50.8 \mathrm{~mm}) . \\
& \mathrm{H}=\text { Depth> } 2 \text { inches }(>50.8 \mathrm{~mm}) .
\end{aligned}
$$

3. Values that indicate patch damage based on the deduct value are shown in Figure 3 below:

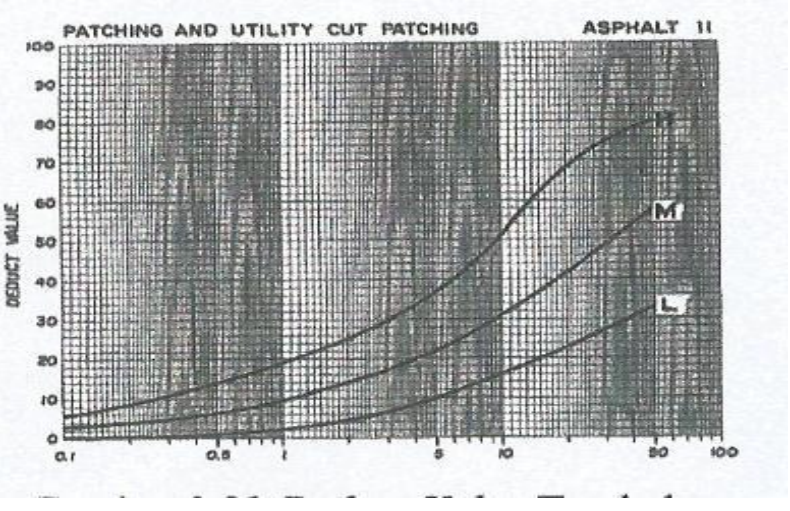

Fig. 3. Edge Distortion Damage Graph 
From figure 3 about edge distortion damage graph, the results obtained from the calculation of density is 0.34 greater than the minimum number shown on the graph, namely 0.1 so that the deduct value is 3 for segments I, II, and III.

Level:

$$
\begin{aligned}
& \mathrm{L}=\text { Area } 10 \mathrm{sqr} \mathrm{ft}\left(0.9 \mathrm{~m}^{2}\right) \\
& \mathrm{M}=\text { Area of } 15 \mathrm{sqr} \mathrm{ft}\left(1.35 \mathrm{~m}^{2}\right) \\
& \mathrm{H}=\text { Area of } 25 \mathrm{sqr} \mathrm{ft}\left(2.32 \mathrm{~m}^{2}\right)
\end{aligned}
$$

- To get the CDV value, you must first know the q value by adding up the deduct value that has been determined on the CDV graph. The value of $q$ is a DV value that is more than 5. From the results of the calculation of Deduct Value then

\begin{tabular}{|c|c|c|c|c|c|c|}
\hline \multirow{2}{*}{ Segment } & \multicolumn{3}{|c|}{$\begin{array}{l}\text { Corrected Deduct Value } \\
\text { (CDV) }\end{array}$} & \multirow{2}{*}{ TOTAL } & \multirow{2}{*}{$\mathbf{q}$} & \multirow{2}{*}{ CDV } \\
\hline & $a$ & $b$ & $c$ & & & \\
\hline I & 19 & 61 & 3 & 83 & 2 & 60 \\
\hline II & 19 & 61 & 3 & 83 & 2 & 60 \\
\hline II & 20 & 63 & 3 & 86 & 2 & 62 \\
\hline
\end{tabular}
it is added in the table as shown in table 2 below:

TABLE II. CALCULATE CORRECTED DEDUCT VALUE (CDV)

From the Corrected Deduct Value (CDV) table, then enter the Total Deduct Value (TDV) graph as in Figure 4 below:

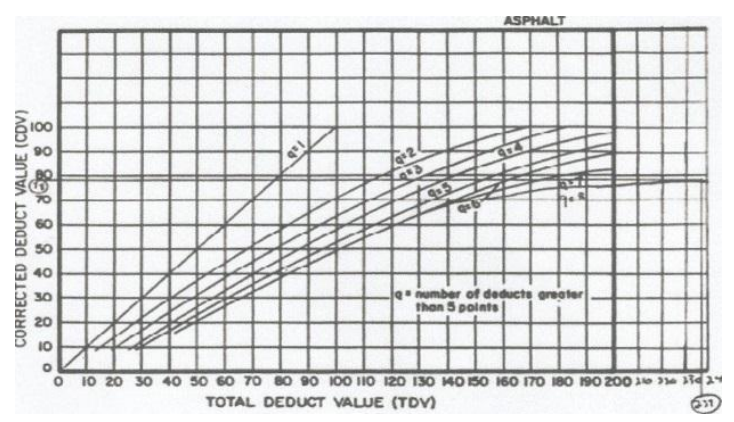

Fig. 4. Corrected Deduct Value (CDV) Graph

In Figure 4, Corrected Deduct Value (CDV) can be seen as the total reduction value on the $\mathrm{X}$ axis, which is 83 and the $\mathrm{q}$ value obtained is 2 , the maximum corrected reduction value $(\mathrm{CDV})$ on the $\mathrm{Y}$ axis of the Sidotopo road segment is 60 for segment I and II, while segment III is 62 .

- Calculating Pavement Condition Index (PCI)

PCI = $100-$ CDV value

By:

$$
\begin{aligned}
& \text { PCI }=\text { Value of pavement conditions } \\
& \text { CDV }=\text { Corrected Deduct Value }
\end{aligned}
$$

So, PCI $=100-60=40$ Poor segment I and II. Whereas $\mathrm{PCI}=100-62=38$ Poor segment III. In accordance with the parameters PCI, the value obtained can indicate the condition of pavement in the segment being reviewed, whether good, very good, or even very bad.

\section{CONCLUSION}

Based on the analysis it can be concluded as follows:

- The average percentage of damage to Sidotopo roads based on their types is:

a) Alligator Cracking is $32 \%$.

b) Potholes is 35\%.

c) Edge Distortion is 33\%.

- Based on the results of the analysis using PCI, obtained the types of causes of the damages and corrective steps.

A. The types of causes of the damages are :

1. Alligator Cracking damage:

a) Construction of pavement is not strong to support the existing traffic load.

b) The surface layer is too thin

c) Selection of a mixture that is too rigid for a thin surface layer.

d) Surface layer fatigue due to traffic load and road life.

e) The carrying capacity of the soil is very low or decreases due to the absorption of water into pavement construction.

f) Stability or compaction of surface layers is not adequate.

2. Potholes damage [12]:

a) Represents the further consequence of road damage including cracks, bumps, grooves, etc, if it is not repaired immediately.

b) The effect of traffic and weather loads (especially rain) will accelerate the formation of holes.

3. Edge Distortion damage: Road damage caused by patching process on road repair that is not perfect.

B. The effort to repair damage in Sidotopo road are [13, 14]:

1. Alligator Cracking damage:

a) Peeling the asphalt that has cracked.

b) Clean the area with comperessor water.

c) Spray the prime coat bonding absorbent layer with a dose of $0.5 \mathrm{lt} / \mathrm{m} 2$.

d) Spread and flatten the mixture of concrete asphalt on the affected surface until smooth

e) Compaction with baby roller for at least 3 tracks.

2. Potholes damage:

a) Improve base courses.

b) Spray the prime coat bonding absorbent layer with a dose of $0.5 \mathrm{lt} / \mathrm{m} 2$

c) Spread and evenly mix the asphalt mixture.

d) Compaction with a baby roller for at least 5 tracks.

3. Edge Distortion damage:

a) Peeling patches that are damaged. 
b) Clean the area with compressor water

c) Spray the prime coat bonding absorbent layer with a dose of $0.5 \mathrm{lt} / \mathrm{m} 2$.

d) Spread and flatten the mixture of concrete asphalt that is damaged until blended

e) Compaction with baby roller for at least 3 tracks.

C. The pavement condition index (PCI) of the Sidotopo road by segment is:

1. Segments I and II are 40, including very poor.

2. Segment III is 38 , including very poor.

\section{ACKNOWLEDGMENT}

Thank you to the Civil Engineering Study Program, especially the Transportation and Traffic Laboratory for its support to completion this research.

\section{REFERENCES}

[1] I. Sholichin and A. Rumintang, "Relation analysis of road damage with excessive vehicles load on Kalianak road Surabaya," J. Phys.: Conf. Ser., vol. 953, pp. 012231_1-012231_5, 2016.

[2] I. Sholichin and N. Utomo, "Road Damage Analysis of Kalianak Road Surabaya,” Adv. Sci. Lett., vol. 23, no. 12, pp. 12295-12299, 2017.

[3] N. Elma, G.D. Holt, Z. Shehu, and I. Endut, "Factors influencing road infrastructure damage in Malaysia," Infrastruct. Asset Manag., vol. 1, pp. 42-52, 2014.

[4] Y.U. Shah, S.S. Jain, D. Tiwari, and M.K. Jain, "Development of Overall Pavement Condition Index for Urban Road Network," Proc. Soc. and Behav. Sci., vol. 104, pp. 332-341, 2013.
[5] M. Mubaraki, "Identification of Pavement Distress Types and Pavement Condition Evaluation Based on Network Level Inspection for Jazan City Road Network," J. of Eng. Res., vol. 11, no. 1, 2014.

[6] Y.S. Mardika, S. Sulistiono, and H. Suyoso, "The Determination of the Repaired Road Priority Using D \& M And PCI Method On The Wonosari - Patemon Road, Bondowoso," $18^{\text {th }}$ FSTPT Int. Symp., Unila, Bandar Lampung, August 28, 2015.

[7] P. K Gupta and P. Atri, "Pavement Surface Distress Evaluation Using PCI”, Int. J. for Res. in Appl. Sci. \& Eng. Technol. (IJRASET), vol. 6, no. 3, pp. 2321-9653, 2018.

[8] G. Vishwanath, Mahdev, M. R. Archana, and K. P. Biligiri, "Development of Pavement Management Strategies for Arterial Roads," Int. J. of Res. in Eng. and Technol. (IJRET), pp. 2321-7308, 2016.

[9] F.M.A. Karim, K.A.H. Rubasi, and A.A. Saleh, "The Road Pavement Condition Index (PCI) Evaluation and Maintenance: A Case Study of Yemen," Organ. Technol. and Manag. in Constr., vol. 8, pp. 1446-1445, 2016.

[10] U. Sharma and Abhishek, "Performance Evaluation of A Road In Chandigarh Using Pavement Condition Index (PCI) Method," Int. Interdiscip. Conf. on Sci. Technol. Eng. Manag. Pharm. and Humanit., 2017.

[11] M.A. Al-Neami, R. H. Al-Rubaee, and Z. J. Kareem, "Evaluation of Pavement Condition Index for Roads of Al-Kut City,” Int. J. of Current Eng. and Technol., vol. 7, no. 4, pp. 2277 - 4106, August 2017.

[12] K. Taehyeong and R. Seung-Ki, "A Guideline for Pothole Classification,” Int. J. of Eng. and Technol., vol. 4, no. 10, October 2014

[13] B. Boyapati, R.P. Kumar, "Prioritisation of Pavement Maintenance based on Pavement Condition Index," Indian J. of Sci. and Technol., vol. 8, Issue 14, July 2015.

[14] M. Tariq, S.S. Pimplikar, "A Comparative Study on Pavement Condition Rating Methods for Flexible Roads,” IJEDR, vol. 5, pp. 2321, 2017. 